Çukurova Üniversitesi Mühendislik Mimarlık Fakültesi Dergisi, 32(3), ss. 47-53, Eylül 2017

Çukurova University Journal of the Faculty of Engineering and Architecture, 32(3), pp. 47-53, September 2017

\title{
Karides Atıklarından Elde Edilen Kitosan Biyopolimerinin Yünlü Kumaşların Antibakteriyel Özellikleri Üzerine Etkisi
}

\author{
Mahmut TAŞ ${ }^{1}$, Emel Ceyhun SABIR ${ }^{* 1}$, Aygül KÜÇÜKGÜLMEZ ${ }^{2}$ \\ ${ }^{1}$ Çukurova Üniversitesi, Mühendislik Mimarlık Fakültesi, Tekstil Mühendisliği Bölümü, Adana \\ ${ }^{2}$ Çukurova Üniversitesi, Su Ürünleri Fakültesi, Avlama ve Işsleme Bölümü, Adana
}

Geliş tarihi: 12.05.2017 Kabul tarihi: 25.09.2017

$\ddot{\mathbf{O} z}$

Bu çalışmada Türkiye'de avcılığı yapılan derin su pembe karidesi (Parapenaeous longirostris) kabuklarından kimyasal yöntem kullanılarak kitosan biyopolimeri elde edilmiştir. Üretilen kitosanın biyopolimeri antibakteriyel özellikler kazandırmak için 3 farklı konsantrasyonda dokunmuş yünlü kumaşlara daldırma metodu ile uygulanmıştır. AATCC-100 standardına göre yünlü kumaşa gerçekleştirilen antibakteriyel aktivite testinin sonuçlarına göre kitosan biyopolimeri uygulanmış kumaşta K.pneumoniae ve S.aureus bakterilerine karşı \%99'un üzerinde aktivite elde edilmiştir. Sonuçlar, Türkiye'de değerlendirilemeyen ve atık olarak ayrılan karides kabuklarının tekstilde de kullanılabilecek antibakteriyel polimere dönüştürülmesi ile kullanılabileceğini göstermiştir.

Anahtar Kelimeler: Karides atıkları, Teknik tekstiller, Antibakteriyel tekstil yapıları, Kitosan

\section{Effect of Chitosan Biopolymer Obtained from Shrimp Wastes on Antibacterial Properties of Woolen Fabrics}

\begin{abstract}
In this study, chitosan biopolymers were obtained by chemical method from the deep water pink shrimp (Parapenaeous longirostris) shells in Turkey. The biopolymer of the produced chitosan was applied by immersion in woven woven fabrics at 3 different concentrations to give antibacterial properties. According to the results of the antibacterial activity test performed on the woolen fabric according to the AATCC-100 standard, over $99 \%$ of the activity against bacterial strains of K.pneumoniae and S.aureus was obtained in the fabric subjected to chitosan biopolymerization. The results show that shrimp shells, which can not be assessed in Turkey and separated as waste, can be used by converting them into antibacterial polymers that can also be used on textiles.
\end{abstract}

Keywords: Shrimp wastes, Technical textiles, Antibacterial textiles, Chitosan

\footnotetext{
"Sorumlu yazar (Corresponding author): Emel Ceyhun SABIR, emelc@cu.edu.tr
} 


\section{GíRiş}

Teknik tekstillerin en önemli konularından biri olan antibakteriyel tekstil yapıları hastaneler, medikal tekstil ürünleri, iç giyim mamülleri gibi geniş kullanım alanları ve birçok yöntem ile üretilebilmeleri ile dikkat çekmektedir. Antibakteriyellik özelliği tekstil yapılarına bitim işlemleri, antibakteriyel hammadden seçimi, tekstil yapısına katılan metalik filamentler ve tekstil yapısının üzerine uygulanan nano-mikro antibakteriyel malzemeler ile kazandırılabilmektedir. Fakat bu durumda bitim işlemlerinin kalıcı olmaması, uygulanan nanomateryallerin toksisitesi, metal filamentlerin tekstil yapısının rijiditesini ve dolayısıyla konfor özelliklerini bozması gibi problemler ortaya çıkmaktadır. Kitosan, genel olarak deniz kabuklularından üretilen kitinin deasetillenmiş türevi olarak bilinmektedir [1]. Deasetilasyon kitin yapısında bulunan asetil gruplarının indirgenmesi işlemidir ve deasetilasyon derecesi de kitin zincir yapısında bulunan asetil gruplarının yüzde kaçının indirgendiğini ifade eder [2]. Sahip olduğu biyobozunurluk, antibakteriyellik, antimantarlık, biyouyumluluk gibi özellikleri ve atık malzemelerden üretilmesi kitosanı tekstil ve birçok diğer sektör için önemli bir biyopolimer haline getirmiştir. Kitosan biyopolimerinin kimyasal yapısı selüloza çok benzemektedir. Selüloz ile kitosan biopolimeri arasındaki tek fark selüloz yapisında bulunan $-\mathrm{OH}$ fonksiyonel gruplardan birinin yerine $-\mathrm{NH}_{2}$ fonksiyonel grubunun bulunmasidır. $\mathrm{Bu}$ durum kitosan biyopolimerinin zincir yapısını polikatyonik olmasını sağlar ve kitosanın birçok üstün özelliği bu polikatyonik yapıdan ileri gelmektedir. $\mathrm{Bu}$ avantajın yanısıra zincir yapisında hem $-\mathrm{OH}$ hem $-\mathrm{NH}$ gruplarının bulunması ve bu grupların farklı şekillerde modifiye edilebiliyor olması da kitosanın kullanımını öne çıkaran bir durumdur. Kitin ve kitosan biyopolimeri ile selüloza ait kimyasal yapıların gösterimi Şekil 1'de verilmiştir.

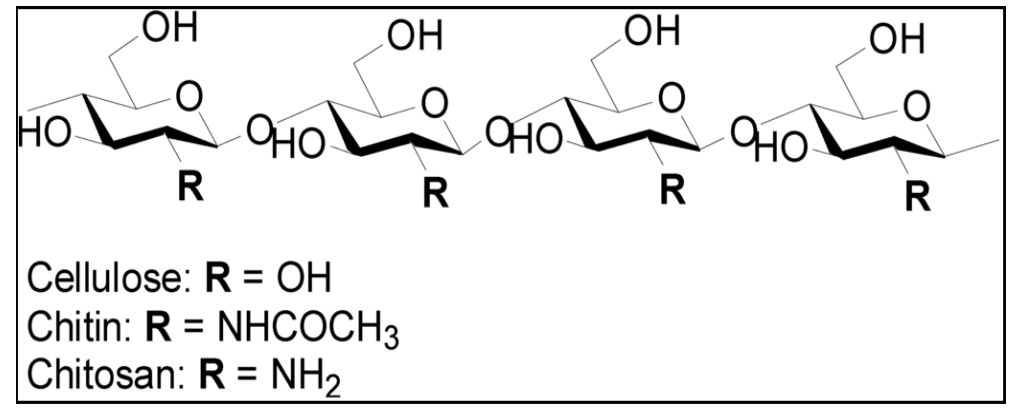

Şekil 1. Selüloz, Kitin ve Kitosanın kimyasal yapısı

Kitosan biyopolimeri; lif, nanoparçacık, mikro parçacık gibi formlarda tekstil malzemelerine antibakteriyellik kazandırmak, boyanabilirliği ve haslıkları artırmak, keçeleşme, çekme gibi sorunları azaltmak için tekstil malzemelerine bitim işlem maddesi olarak, fulard yoluyla uygulanabilmektedir. Literatürde kitosanın konvansiyonel tekstil yapılarına antibakteriyellik kazandırmak amacıyla kullanıldığı birçok çalışmaya rastlanmaktadır. Shin ve arkadaşları (1999) polipropilen dokusuz yüzey yapılarına antibakteriyel özellikler kazandırmak için kitosan oligomerlerini uygulamışlardır. Kitosanın \%0.01 uygulamasında dahi \%90'ın üzerinde antibakteriyel etki gösterdiği tespit edilmiştir [3].

Erra ve arkadaşları (1999) kitosan uygulanmış yünlü kumaşların çekmezlik özellikleri test etmişlerdir. Uygulama sonucunda yünlü kumaşların çekme problemlerinin kitosan ile iyileştirilebildiği görülmüştür [4]. $\mathrm{Hu}$ ve arkadaşları (2002) tarafindan grafting metodu ile kitosan polimer zincirleri polyester liflerine bağlanmıştır. Çalışmada üretilen yapıların patojenik bakterilere karşı aktiviteleri ölçülmüş ve yüksek aktivite gözlemlenmiştir [5]. Öktem (2003) pamuk ve pamuk/polyester kumaşlara kitosan 
uygulamış ve çeşitli özelliklerini test etmiştir. Kitosan uygulanan kumaşların yüksek antibakteriyel özellik gösterdiği görülmüștür [6]. Khaled ve arkadaşları (2005) pamuk kumaşa kitosan uygulamış ve farklı çapraz bağlayıcılardaki antibakteriyel özelliklerini araştırmışlardır. Çalı̧̧ma sonunda kitosanın konvansiyonel pamuklu kumaşa yüksek antibakteriyel özelliği $\% 0,25$ konsantrasyonda dahi sağladığı görülmüştür [6].

Deng ve arkadaşları (2006) tarafindan keten kumaşlara kitosan uygulanmış, buruşma ve antibakteriyel özellikleri test edilmiştir. Çalışmada kitosanın yüksek antibakteriyellik yanısıra buruşmazlık özelliği sağladığı görülmüştür. $\mathrm{Bu}$ çalışmada kitosanın tekstilde birçok amaçla kullanılabileceği gösterilmiştir [7]. Tseng ve arkadaşları (2009) Poliamid tekstil yüzeylerine açık air plasma yöntemiyle radikaller oluşturarak graft edilmiş ve oluşturulan yüzeylerin antimikrobiyal özellikleri test edilmiştir. Çalışma sonunda kitosan oligomerine göre polimer graft etmenin daha etkin antibakteriyel sonuçlar oluşturduğu görülmüştür [8]. Higazy ve arkadaşları (2010) jüt tekstil ambalajların antimikrobiyal özelliklerini geliştirmek amacıyla kitosanı metal kompleksler ile birlikte uygulamıştır. Elde edilen yapıların antimikrobiyal ve antifungal özelliklerinin ikisini de taşıdığı gözlemlenmiştir [9]. Gebeish ve arkadaşları (2011) pamuk kumaşlara ucuz ve kalıcı antibakteriyel etki sağlamak amaciyla kitosan polimerini kullanmışlardır. Kumaşların en az 10 yıkamaya dayanıklı olacak şekilde antibakteriyel özellik kazandırıldığ 1 görülmüştür [10]. Bu çalışmada, kitosan biyopolimerinin karides kabuklarından üretimi ve yünlü kumaşlara farklı oranlarda uygulanması ile antibakteriyel özelliklerin üzerine etkisinin araştırılması hedeflenmiştir.

\section{DENEYSEL ÇALIŞMALAR}

\subsection{Materyal}

Kitosan biyopolimerinin üretimi için derin su pembe karidesi (Parapenaeous longirostris) kabukları kullanılmıștır. Üretim prosesinde kullanılan Sodyum hidroksit, Hidroklorik asit ve
Hidrojen peroksit Sigma Aldrich (USA) firmasından, kitosan biyopolimerinin çözündürülmesi için kullanılan asetik asit Merck (USA) firmasından, karides kabuklarından elde edilen kitosanın özelliklerini kıyaslamak amacı ile kullanılan yüksek deasetilasyon derecesine sahip kitosan (\%75-85) Sigma Aldrich'den temin edilmiştir. Üretilen kitosanın uygulanacağı tekstil yüzeyi Yünsa A.Ş. (Türkiye) firmasından temin edilmiş olup \%100 yün liflerinden üretilmiş dokuma kumaştır. Çalışmada biyopolimer uygulanmamış yünlü kumaş referans kumaş olarak kullanılmıştır.

\subsection{Metod}

\subsubsection{Kitosan Biyopolimerinin Üretimi}

Kitosan biyopolimerinin üretimi için Küçükgülmez ve arkadaşlarının uyguladığ kimyasal yöntem kullanılmıştır[11]. Bu amaçla Ege bölgesinde bulunan su ürünleri işleme fabrikasindan derin su pembe karidesi (Parapenaeous longirostris) işleme atıkları temin edilmiş ve laboratuvarda sadece kabuk kısımları ayrılmıştır. Üretim, deproteinizasyon, deminerilizasyon, dekolorizasayon ve deasetilasyon olmak üzere 4 aşamada gerçekleştirilmiştir.

\subsubsection{Kitosanın Karakterizasyonu}

Çalışmada karides kabuklarından elde edilen kitosanın nem içeriği etüvde $105^{\circ} \mathrm{C}$ 'de, ham kül içeriği ise yakma firınında $530{ }^{\circ} \mathrm{C}$ 'de sabit ağırlığa ulaşana kadar yakılarak tespit edilmiştir. Deasetilasyon derecesi \% olarak potentiometrik titrasyon yöntemiyle belirlenmiştir [12]. Molekül ağırlığı Wang ve arkadaşlarının uyguladığı yönteme göre yapılmıştır [13]. Viskozite ölçümü için asetik asit çözeltisi (\%1'lik) içerisinde \%1'lik kitosan solüsyonu hazırlanmıştır. Çözünmeyen materyallerin uzaklaştırılması için kitosan çözeltisi filtre kâğıdından geçirilmiş ve viskozite ölçümleri otomatik viskozimetre yardımıyla ölçülmüştür. Su ve yağ tutma kapasitesini belirlemede Wang ve Kinsella (1976)'nın uyguladığı yöntem kullanılmıştır [14]. 
Karides Atıklarından Elde Edilen Kitosan Biyopolimerinin Yünlü Kumaşların Antibakteriyel Özellikleri Üzerine Etkisi

\subsubsection{Yünlü Kumaşa Kitosan Biyopolimerinin Uygulanması}

Öncelikle karides kabuklarından üretilen ve ticari kitosan biyopolimeri \%0,25, \%0,75, \%1,25 şeklinde 3 farklı konsantrasyonda \%1'lik asetik asit karışımında çözündürülerek kitosan biyopolimeri içeren ve kumaşlara uygulamada kullanılacak olan çözeltiler elde edilmiştir. Ardından uygulama yapılacak tekstil yüzeyleri alkol ile yıkanmış ve safsızlıkların giderilmesi sağlanmıştır. Yıkama sonrası tekstil numuneleri oda sıcaklığında kurutulmuş ve daha sonra hazırlanan çözeltilere daldırılarak etüv ortamında $95{ }^{\circ} \mathrm{C}$ sicaklıkta kurutulmuştur. Üzerinde asit kalıntısı kalmaması için kuru numuneler $0,1 \mathrm{~N}$ Sodyumhidroksit çözeltisinden geçirilmiş ve saf su ile yıkamaya tabi tutulmuştur. Kumaşın çözeltiye daldırılması ve elde edilen numunenin görüntüsü Şekil 2'de verilmiştir.
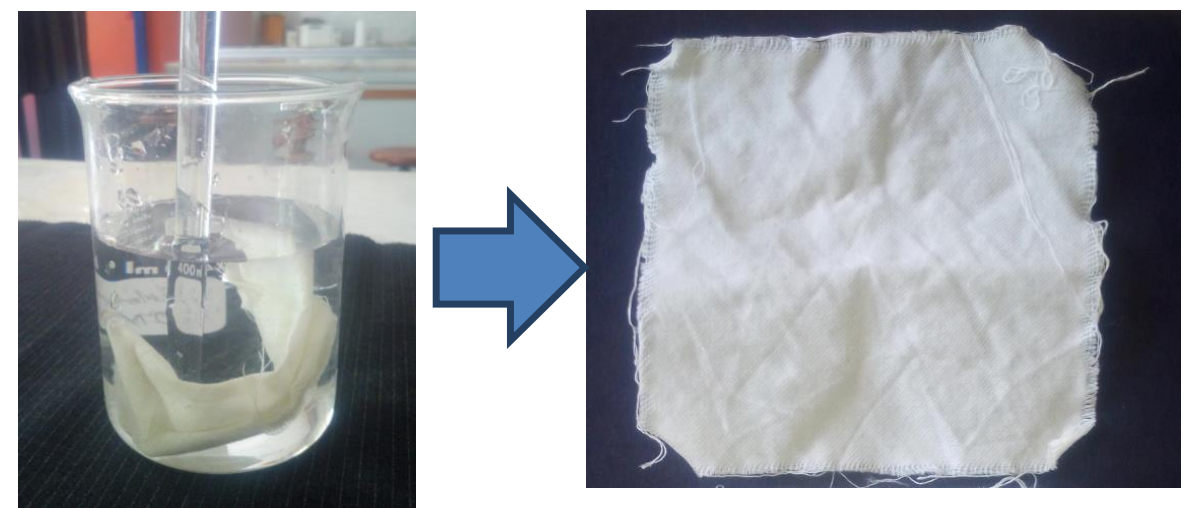

Şekil 2. Yünlü kumaşın Kitosan çözeltisine daldırılması ve elde edilen numune parçalarının görünüm

\subsubsection{Antibakteriyel Aktivite Testi}

Kitosan uygulanmış kumaş parçalarının antibakteriyel aktivitelerinin tespitinde AATCC-100 standardı kullanılmıştır. Bu standarda göre K.pneumoniae ve S.aureus bakterileri kullanılmış ve antibakteriyel aktivite testinde karides kabuklarından üretilen ve ticari olarak temin edilen kitosanın uygulandığı kumaşlar kullanılmıştır. $\mathrm{Bu}$ test için numune kumaştan dairesel olarak 3,8 $\mathrm{mm}$ çapında örnekler hazırlanmış ve ilgili standarda göre deney gerçekleştirilmiştir. Sonuçların yorumlanması referans kumaş ile ticari ve üretilen kitosan uygulanmış kumaşlarda inhibe olmamış bakterilerin sayılması ile sağlanmıştır.

\section{SONUÇLAR VE TARTIŞMA}

\subsection{Kitosan Biyopolimerinin Karakterizasyonu}

Karides kabuklarından elde edilen kitosanın fizikokimyasal özellikleri; nem, ham kül, deasetilasyon derecesi, molekül ağırlığı, viskozite, su ve yağ tutma kapasitesi; Çizelge 1'de verilmiştir.

Çizelge 1. Üretilen kitosan biyopolimerinin ölçülen özellikleri

\begin{tabular}{|l|c|}
\hline Ölçülen Fizikokimyasal Özellik & Değer \\
\hline Nem (\%) & $1,52 \pm 0,04$ \\
\hline Ham kül (\%) & $0,18 \pm 0,07$ \\
\hline Deasetilasyon Derecesi (\%) & $93,70 \pm 2,20$ \\
\hline Molekül Ağırlığı (kDa) & $2,15 \pm 0,04$ \\
\hline Viskozite (Cp) & $150,00 \pm 43,58$ \\
\hline Su Tutma Kapasitesi (\%) & $654,16 \pm 23,32$ \\
\hline Yağ Tutma Kapasitesi (\%) & $692,30 \pm 30,12$ \\
\hline
\end{tabular}

Bu çalışmada, potentiometrik titrasyon yöntemiyle belirlenen deasetilayon derecesi \%93,70 olarak tespit edilmiştir. Kitosanın deasetilasyon 
derecesinin yüksek olması nedeni ile viskozite ve molekül ağırlığı, su ve yağ tutma kapasiteleri düşük bulunmuştur. Benzer şekilde Jeon ve arkadaşları (2001) kitosanın bu özelliklerinin deasetilasyon süresi ile yakından ilişkili olduğunu ve kitosanın kısa deasetilasyon süresinde en yüksek vikositeye sahip olduğunu bildirmişlerdir [15].

Kitosanın tüm bu fizikokimyasal özellikleri; kullanılan kabuklu türüne, kitosanın elde ediliş yöntemine, deasitilasyon süresi, sıcaklık, $\mathrm{NaOH}$ konsantrasyonu gibi üretim parametrelerine göre oldukça değişkenlik gösterebilmektedir.

\section{2. Üretilen Kumaş Numunelerine Antibakteriyel Aktivite Sonuçları}

Karides kabuklarından elde edilen ve ticari olarak temin edilen kitosanın K.phenomenia ve S.aureus bakterilerine karşı antibakteriyel aktivite test sonuçlarının görsel durumu Şekil 3'de verilmiştir.

Sonuçlar incelendiğinde; ticari ve üretilen kitosanın referans kumaş ile kıyaslandığında her iki bakteri için de \%99 ve üzeri şeklinde oldukça yüksek antibakteriyel aktivite gösterdiği tespit edilmiştir. $\mathrm{Bu}$ çalışmada karides kabuklarından üretilen kitosan biyopolimerinin hem K.pneumoniae hemde S.aureus'a karşı ticari olarak temin edilen kitosana göre antibakteriyel etkisinin daha yüksek olduğu görülmüştür. Kitosanın özelliklerinden deasetilasyon derecesi, molekül ağırlığı ve viskozitesi antibakteriyel aktivite açısından oldukça önem arz etmektedir. Karides kabuklarından üretilen kitosanın ticari kitosana göre daha yüksek deasetilasyon derecesine sahip olması antibakteriyel aktivite sonuçlarınında daha yüksek çıkmasına neden olmuştur. Tsai ve arkadaşları (2002)'de deasetilasyon derecesinin arttıkça antimikrobiyal aktivitenin arttığını bildirmişlerdir [16]. Yün lifinin genel olarak antimikrobiyel etki göstermediği bilinmektedir. Elde edilen sonuçlar yün lifinden üretilen dokuma kumaşların antibakteriyel etki kazanmasını ve buna bağlı olarak farklı kullanım alanlarına hitap etmesini sağlayacak veriler içermektedir.

\section{TEȘEKKÜR}

Bu çalışma, Çukurova Üniversitesi Rektörlüğü Bilimsel Araştırma Projeleri Birimi tarafından desteklenmektedir (Proje kodu: FBA-2017-7350).

Açıklama: Bu çalışmanın bir kısmı; "Investigation Of Antibacterial Activity of Chitosan Threated Wool Fabrics, 1st International Mediterranean Science and Engineering Congress (IMSEC 2016) 26-28 October 2016, Adana/Turkey" adiyla uluslararası bir kongrede sunulmuş olup bildirinin özeti, kongre özet kitapçığında yer almıștır.

\section{KAYNAKLAR}

1. Abdou, E.S., K.S.A., Nagy, M.Z., 2008. Elsabee, Extraction and Characterization of Chitin and Chitosan from Local Sources. Bioresource Technology, 99(5): p. 1359-1367.

2. Wu, J.Y., 2008. Research on Mechanism of Deacetylation of Chitin. Rare Metal Materials and Engineering, 37: 718-722.

3. Shin, Y., Yoo, D.I., Min, K., 1999. Antimicrobial Finishing of Polypropylene Nonwoven Fabric by Treatment with Chitosan Oligomer. Journal of Applied Polymer Science, 74(12): 2911-2916.

4. Erra, P., Molina, R., Jocic, D.M., Julia, R., Cuesta, A., Tascon, J.M.D., 1999. Shrinkage Properties of Wool Treated with Low Temperature Plasma and Chitosan Biopolymer. Textile Research Journal, 69(11): 811-815.

5. Hu, S.G., C.H. Jou, M.C., 2002. Yang, Surface Grafting of Polyester Fiber with Chitosan and the Antibacterial Activity of Pathogenic Bacteria. Journal of Applied Polymer Science, 86(12): 2977-2983.

6. Oktem, T., 2003. Surface Treatment of Cotton Fabrics with Chitosan. Coloration Technology, 119(4): 241-246.

7. El-Tahlawy, K.F., El-bendary A., Elhendawy, A.G., Hudson, S.M., 2005. The Antimicrobial Activity of Cotton Fabrics Treated With Different Crosslinking Agents and Chitosan. Carbohydrate Polymers, 60(4): 421-430.

8. Tseng, H-J., Hsu, S., Wu, M-W., Hsueh, T-H., Tu, P-C., 2009. Nylon Textiles Grafted with Chitosan by Open Air Plasma and their 
Antimicrobial Effect. Fibers and Polymers, 10(1): 53-59.

9. Higazy, A., Hashem, M., Shafei, A.E., Hady, M.A., 2010. Development of Antimicrobial Jute Packaging using Chitosan and Chitosanmetal Complex. Carbohydrate Polymers, 79(4): 867-874.

10. Hebeish, A., Abdel-Mohdyet, F.A., Fouda, M.M.G., Elsaid, Z., Essam, S., Tammam, G.H., Dreesc, E.A., 2011. Green Synthesis of Easy Care and Antimicrobial Cotton Fabrics. Carbohydrate Polymers, 86(4): 1684-1691.

11. Kucukgulmez, A., Celik, M., Yanar, Y., Sen, D., Polat, H., Kadak, E., 2011. Physicochemical Characterization of Chitosan Extracted from Metapenaeus Stebbingi Shells. Food Chemistry, 126(3): 1144-1148.

12. Tolaimate, A.J., Desbrières, M., Rhazi Alagui A., Vincendon, M., Vottero, P., 2000. On the Influence of Deacetylation Process on the Physicochemical Characteristics of Chitosan from Squid Chitin. Polymer, 41(7): 2463-2469.

13. Wang, Q.Z., Chen, X.G., Liu, N.S., Wang, X.C., Liu, S.X., Meng, H., Liu, C.G., 2006. Protonation Constants of Chitosan with Different Molecular Weight and Degree of Deacetylation. Carbohydrate Polymers, 65(2): 194-201.

14. Wang, J.C., Kinsella, J.E., 1976. Functional Properties of Novel Proteins: Alfalfa Leaf Protein. Journal of Food Science, 41(2): 236.

15. Jeon, Y.J., Park, P.J., Kim, S.K., 2001. Antimicrobial Effect of Chitooligosaccharides Produced by Bioreactor. Carbohydrate Polymers, 44(1): 71-76.

16. Tsai, G.J., Su, W.H., Chen, H.C., Pan, C.L., 2002. Antimicrobial Activity of Shrimp Chitin and Chitosan from Different Treatments and Applications of Fish Preservation. Fisheries Science, 68(1): 170-177. 


\begin{tabular}{|c|c|c|}
\hline \multirow{2}{*}{ Deney Numunesi } & \multicolumn{2}{|c|}{ Bakteriler } \\
\hline & K.pneumoniae & S.aureus \\
\hline Referans kumaş & & \\
\hline Asetik Asit Uygulanmış Kumaş & & \\
\hline $\begin{array}{l}\% 0,25 \text { konsantrasyonda kitosan uygulanmış kumaş } \\
\text { (Karides kabuklarından üretilen) }\end{array}$ & & \\
\hline $\begin{array}{l}\% 0,75 \text { konsantrasyonda kitosan uygulanmış kumaş } \\
\text { (Karides kabuklarından üretilen) }\end{array}$ & & \\
\hline $\begin{array}{l}\% 1,25 \text { konsantrasyonda kitosan uygulanmış kumaş } \\
\text { (Karides kabuklarından üretilen) }\end{array}$ & & \\
\hline $\begin{array}{l}\% 0,25 \text { konsantrasyonda kitosan uygulanmış kumaş } \\
\text { (Ticari olarak temin edilen) }\end{array}$ & & \\
\hline $\begin{array}{l}\% 0,75 \text { konsantrasyonda kitosan uygulanmış kumaş } \\
\text { (Ticari olarak temin edilen) }\end{array}$ & & \\
\hline $\begin{array}{l}\% 1,25 \text { konsantrasyonda kitosan uygulanmış kumaş } \\
\text { (Ticari olarak temin edilen) }\end{array}$ & & \\
\hline
\end{tabular}

Şekil 3. K. Pneumoniae ve S.Aureus bakterilerine karşı antibakteriyel aktivite testi sonuçları 
